\title{
Kepatuhan Wajib Pajak Orang Pribadi Ditinjau dari Kemudahan Penerapan Sistem E-Filing Dan Pengetahuan Perpajakan
}

\author{
Indra Wijaya ${ }^{1, *}$, Desi Komala Sari ${ }^{1}$ \\ 1,* Universitas Bina Insani: Jalan Raya Siliwangi no.6 Rawa Panjang Bekasi Timur \\ 17114 Indonesia. Telp. (021) 82436886 / (021) 82436 996. e-mail: \\ indraldfpw@gmail.com,desikomala72@gmail.com
}

*Korespondensi: email: indraldfpw@gmail.com

Diterima: 13 Nopember 2019; Review: 20 April 2020; Disetujui: 01 Mei 2020

Cara Sitasi: Wijaya I, Sari DK. 2020. Kepatuhan Wajib Pajak Orang Pribadi Ditinjau dari Kemudahan Penerapan Sistem E-filing dan Pengetahuan Perpajakan. Jurnal Online Insan Akuntan. Vol. 5 (1): 1-12.

\begin{abstract}
Abstrak: Penelitian ini bertujuan untuk mengetahui pengaruh Kemudahan Penerapan Sistem E-Filing Dan Pengetahuan Perpajakan Terhadap Kepatuhan Wajib Pajak. Data penelitian ini diperoleh dari kuesioner (primer) yang dibagikan kepada Wajib Pajak PT. PLN (Persero) Tbk UP3 Tanjung Priok dengan menggunakan metode accidental sampling. Populasi penelitian ini adalah Wajib Pajak Orang Pribadi PT. PLN (Persero) Tbk UP3 Tanjung Priok. Sampel yang digunakan pada penelitian ini sebanyak 30 responden. Kuesioner ini di uji dengan uji valditas dan uji reliabilitas sebelum penelitian. Uji asumsi klasik yang digunakan adalah uji normalitas, uji multikolinieritas, uji heteroskedastisitas, dan uji autokorelasi. Uji hipotesis yang digunakan adalah regresi linier berganda. Hasil penelitian ini menunjukkan bahwa (1) Kemudahan Penerapan Sistem E-Filing tidak berpengaruh signifikan terhadap Kepatuhan Wajib Pajak. (2) Pengetahuan Perpajakan berpengaruh positif terhadap kepatuhan Wajib Pajak.
\end{abstract}

Kata Kunci: E-Filing, Kepatuhan Wajib Pajak, Pengetahuan Perpajakan.

Abstract: This research aimed to know the influence of the Ease of Application the Tax E-Filing and Knowledge System on Taxpayer Compliance. The research data was obtained from the questionnaire (primary) which was distributed to the Taxpayers of PT. PLN (Persero) Tbk UP3 Tanjung Priok the sample of this research used the accidental sampling method. The populations of this research were the Individual Taxpayer of PT. PLN (Persero) Tbk UP3 Tanjung Priok. The sample of this research used the 30 respondents. This questionnaire was tested by validity test and reliability test before the research. The classic assumption test used the normality test, multicollinearity test, heteroscedasticity test, and autocorrelation test. The hypothesis test was used multiple linear regression. The results of this research showed that (1) Ease of Application of the E-Filing System has no significant effect on Taxpayer Compliance. (2) Tax knowledge has a positive effect on taxpayer compliance.

Keywords: E-Filing, Taxpayer Compliance, Tax Knowledge.

\section{Pendahuluan}

Sumber pendapatan negara yang dimanfaatkan untuk mendanai pengeluaran pemerintah dan infastruktur nasional di antaranya adalah bersumber dari penerimaan pajak serta penerimaan bukan pajak. Penerimaan-penerimaan ini secara tidak langsung 
berdampak kepada kemakmuran dan kesejahteraan rakyat. Penerimaan pajak adalah kontribusi wajib dari orang pribadi atau badan kepada negara yang terutang sifatnya memaksa berdasarkan Undang-Undang (Yogatama dan Meiranto, 2014).

Sistem pemungutan pajak digolongkan menjadi 3 jenis: yaitu 1) Official Assessment System; 2) Self Assessment System dan 3) Withholding System (Resmi, 2017). Sedangkan sistem perpajakan yang diterapkan atau berlaku di Indonesia yaitu self assessment system, di mana wajib pajak diberi kewenangan untuk menghitung, memotong, membayar serta melaporkan sendiri pajak terutang ke kantor pajak dengan berlandaskan undang-undang terkait (Hanifah dan Wijaya, 2019). Self assessment system sangat bergantung kepada kesadaran Wajib Pajak dalam mematuhi kewajiban perpajakannya, karena masih banyak Wajib Pajak yang belum patuh dalam hal melaporkan dan membayar pajak (Agustiningsih dan Isroah, 2016).

Direktorat Jenderal Pajak (DJP) menyimpulkan bahwa pada tahun 2019 jumlah pajak yang dilaporkan masih tergolong rendah, yaitu SPT yang dilaporkan hanya 10,9 juta atau $70 \%$ dari target 15,5 juta WP. Persentase $70 \%$ dari target ini lebih rendah apabila dibandingkan capaian 2018 yang mencapai 74\% dari target. Pertumbuhan pelaporan SPT per 31 Maret 2019 pun hanya 3,8\% yang merupakan jumlah yang lebih rendah apabila dibandingkan dengan tahun lalu yang mencapai 14\%. Proses menuju peningkatan kepatuhan wajib pajak adalah upaya yang berkelanjutan, karena semakin tinggi tingkat kepatuhan wajib pajak, maka akan meningkatkan basis pemajakan (https://www.pajak.go.id).

Salah satu faktor yang kemungkinan mempengaruhi kepatuhan wajib pajak adalah penerapain sistem E-Filling. Tersedianya sistem pelaporan pajak menggunakan e-filing sangat memudahkan Wajib Pajak. Wajib Pajak bisa melaporkan SPT-nya kapanpun dalam 24 jam selama 7 hari. Kemudahan ini berarti wajib pajak dapat melaporkan SPT-nya walaupun pada hari libur (Agustiningsih dan Isroah, 2016).

Faktor lainnya yang dapat mempengaruhi kepatuhan wajib pajak adalah pengetahuan dalam hal perpajakan. Penguasaan akan peraturan perpajakan oleh wajib pajak dapat meningkatkan kepatuhan wajib pajak. Wajib pajak akan berusaha menyelesaikan kewajibannya supaya terhindar dari sanksi-sanksi yang terdapat pada peraturan perpajakan (Rahayu, 2017). Pemahaman yang kurang mumpuni mengenai pajak dapat berakibat pada kurangnya kesadaran wajib pajak dalam membayar pajak. Wajib pajak merasa kurang tertarik dalam membayar pajak karena merasa tidak 
mendapatkan insentif atau timbal balik secara langsung untuk mereka (Ilhamsyah et al, 2016).

Tujuan penelitian ini adalah untuk mengetahui pengaruh kemudahan penerapan sistem e-filing dan pengetahuan perpajakan terhadap kepatuhan wajib pajak secara parsial dan secara simultan pada PT. PLN (Persero) Tbk UP3 (Unit Pelaksana Pelayanan Pelanggan) Area Tanjung Priok.

\section{Perumusan Hipotesis}

Pengertian E-Filling menurut Peraturan Direktorat Jenderal Pajak Nomor PER1/PJ/2014 yaitu suatu cara penyampaian SPT Tahunan dengan media elektronik yang dilakukan secara online serta real time website yang telah disediakan (www.pajak.go.id) atau lewat perusahaan penyedia jasa aplikasi. E-Filling sangat menguntungkan wajib pajak dalam melaporkan pajaknya karena memberikan kemudahan serta biaya yang lebih murah dibandingkan pelaporan secara manual, serta dengan proses lebih cepat karena wajib pajak dapat merekam sendiri surat pemberitahuannya (Sulistyorini, et al, 2017).

Hasil penelitian Sulistyorini, et al (2017) menunjukkan bahwa penerapan sistem $e$-filing berpengaruh positif terhadap kepatuhan Wajib Pajak. Penelitian yang dilakukan oleh Agustiningsih dan Isroah (2016) juga memperoleh hasil bahwa penerapan sistem $e$ filing berpengaruh positif terhadap kepatuhan Wajib Pajak.

\section{Berdasarkan uraian tersebut, maka hipotesis yang diusulkan adalah:}

$\mathrm{H}_{1}$ : Kemudahan Penerapan sistem e-filing berpengaruh positif terhadap kepatuhan Wajib Pajak Orang Pribadi Pegawai PT. PLN (Persero) Tbk UP3 Tanjung Priok.

Pengetahuan mengenai peraturan perpajakan dapat meningkatkan kemauan Wajib Pajak untuk memenuhi kewajiban perpajakannya, karena Wajib Pajak yang memahami peraturan pajak mayoritas berpikiran bahwa lebih baik membayar pajak daripada dikenakan sanksi pajak (Handayani, et al). Hasil penelitian Rahayu (2017) yaitu pengetahuan perpajakan berpengaruh positif terhadap kepatuhan Wajib Pajak. Penelitian Ilhamsyah et al (2016) juga memperoleh hasil serupa yaitu pengetahuan perpajakan berpengaruh positif terhadap kepatuhan Wajib Pajak. 


\section{Berdasarkan uraian tersebut, maka hipotesis yang diusulkan adalah:}

$\mathrm{H}_{2}$ : Pengetahuan Perpajakan berpengaruh positif terhadap kepatuhan Wajib Pajak Orang Pribadi Pegawai PT. PLN (Persero) Tbk UP3 Tanjung Priok.

\section{Metode Penelitian}

Jenis data yang digunakan pada penelitian ini adalah data primer aktif. Data primer aktif yaitu data yang diperoleh dengan survei lapangan atau hasil observasi melalui penyebaran kuesioner. Pengolahan data menggunakan kuesioner yang pertanyaannya mengarah kepada indikator-indikator pada setiap variabel yang diteliti. Penelitian ini menggunakan populasi perusahaan monopoli PT. PLN (persero) Tbk UP3 Tanjung Priok. Pemilihan sampel dalam penelitian ini dilakukan dengan metode accidental sampling dengan menggunakan beberapa pegawai PT. PLN (Persero) UP3 Tanjung Priok yang sudah atau pernah menggunakan sistem $e$-filing.

Teknik analisis dalam penelitian ini menggunakan metode deskriptif. Selanjutnya untuk dasar pengolahan, kuesioner disusun berdasarkan urutan data yang diperlukan dan jawaban yang tepat menurut responden yang dipilih dengan memberikan tanda ceklis pada skala yang dipilih. Skala pengukuran yang digunakan adalah skala likert. Analisis dilakukan untuk mengetahui ada tidaknya pengaruh kemudahan penerapan sistem $e$ filing dan pengetahuan perpajakan sebagai variabel bebas (independent variable) terhadap kepatuhan wajib pajak sebagai variabel terikat (dependent variable).

Persamaan regresi penelitian ini adalah sebagai berikut:

$\mathrm{Y}=\mathrm{a}+\mathrm{b}_{1} \mathrm{X}_{1}+\mathrm{b}_{2} \mathrm{X}_{2}+\mathrm{e}$

Keterangan:

$\mathrm{Y} \quad=$ Kepatuhan Wajib Pajak

a $\quad=$ Konstanta

$b_{1}, b_{2}=$ Koefisien Regresi

$\mathrm{X}_{1} \quad=$ Variabel Kemudahan Penerapan Sistem $e$-filing

$\mathrm{X}_{2}=$ Variabel Pengetahuan Perpajakan

$\mathrm{E}=$ error

Data dianalisis menggunakan software SPSS Statistic 25. Hasil analisis akan diuji kembali menggunakan uji asumsi klasik dan uji analisis regresi linear berganda, 
yang terdiri dari: 1) Uji Analisis Deskriptif dan 2) Uji Asumsi Klasik, terdiri dari Uji Normalitas, Uji Autokorelasi, Uji Multikolinearitas, Uji Heteroskedastisitas.

\section{Hasil dan Pembahasan}

Uji Analisis Deskriptif

Tabel 1 Hasil Analisis Statistik Deskriptif

\begin{tabular}{lccccc}
\hline \multicolumn{1}{c}{ Variabel } & N & Min & Max & Mean $\begin{array}{l}\text { Standar } \\
\text { Deviasi }\end{array}$ \\
\hline $\begin{array}{l}\text { Kemudahan Penerapan Sistem } e- \\
\text { filing }\end{array}$ & 30 & 3,2 & 4,8 & 3,9 & 0,37 \\
$\begin{array}{l}\text { Pengetahuan Perpajakan } \\
\text { Kepatuhan WPOP }\end{array}$ & 30 & 2,9 & 4,9 & 3,7 & 0,45 \\
\end{tabular}

Sumber: Hasil Pengolahan Data (2019)

Tabel 1 menunjukkan bahwa kemudahan sistem E-Filling memiliki nilai rata-rata 3,9, nilai minimal 3,2, nilai maksimal 4,8, serta standar deviasi senilai 0,37 . Variabel pengetahuan perpajakan memiliki nilai rata-rata 3,7, nilai minimal 2,9, nilai maksimal 4,9, serta standar deviasi senilai 0,45. Variabel kepatuhan wajib pajak orang pribadi memiliki nilai rata-rata 3,7 , nilai minimal 2,5 , nilai maksimal 4,5, serta standar deviasi senilai 0,52 .

\section{Uji Asumsi Klasik}

a. Uji Multikolinearitas

Tabel 2 Hasil Uji Multikolinearitas

\begin{tabular}{|c|c|c|c|}
\hline \multirow[t]{2}{*}{ Variabel } & \multicolumn{2}{|c|}{ Perhitungan } & \multirow[t]{2}{*}{ Keterangan } \\
\hline & Tolerance & VIF & \\
\hline Kemudahan & 0,827 & 1,209 & Tidak terjadi \\
\hline Sistem $e$-filing & & & Multikolinearitas \\
\hline Pengetahuan Perpajakan & 0,827 & 1,209 & $\begin{array}{c}\text { Tidak terjadi } \\
\text { Multikolinearitas }\end{array}$ \\
\hline
\end{tabular}

Sumber: Hasil Pengolahan Data (2019)

Tabel 2 menunjukkan semua variabel bebas mempunyai nilai Tolerance $0,827 \geq$ 0,10 dan nilai VIF $1,209 \leq 10$. Dengan demikian, dapat disimpulkan bahwa seluruh variabel bebas dalam penelitian ini tidak terjadi multikolinearitas. 
b. Uji Heteroskedastisitas

Tabel 3 Hasil Uji Heteroskedastisitas

\begin{tabular}{lcc}
\hline \multicolumn{1}{c}{ Variabel } & Sig & Keterangan \\
\hline Kemudahan Penerapan Sistem $e$-filing & 0,113 & Tidak terjadi Heteroskedastisitas \\
Pengetahuan Perpajakan & 0,791 & Tidak terjadi Heteroskedastisitas \\
\hline
\end{tabular}

Sumber: Hasil Pengolahan Data (2019)

Tabel 3 menunjukkan bahwa semua variabel bebas mempunyai nilai probabilitas signifikansi lebih besar dari > 0,05. Dengan demikian, hal ini dapat disimpulkan bahwa tidak terjadi heteroskedastisitas dalam model regresi.

c. Uji Normalitas

Tabel 4 Hasil Uji Normalitas

\begin{tabular}{llr}
\hline \multicolumn{2}{c}{ One-Sample Kolmogorov-Smirnov Test } \\
\hline & & $\begin{array}{c}\text { Unstandardized } \\
\text { Residual }\end{array}$ \\
\hline $\mathrm{N}$ & & 30 \\
\hline Normal Parameters ${ }^{\mathrm{a}, \mathrm{b}}$ & Mean & 0,0000000 \\
& Std. & 0,46681250 \\
& Deviation & \\
\hline Most Extreme & Absolute & 0,087 \\
Differences & Positive & 0,080 \\
& Negative & $-0,087$ \\
\hline Test Statistic & & 0,087 \\
\hline Asymp. Sig. (2-tailed) & & $0,200^{\mathrm{c}, \mathrm{d}}$ \\
\hline
\end{tabular}

Sumber: Hasil Pengolahan Data (2019)

Tabel 4 menunjukkan bahwa dapat diketahui nilai Kolmogorov smirnov adalah 0,200 yang berarti lebih besar dari $>0,05$, maka dapat disimpulkan data terdistribusi secara normal.

d. Uji Autokorelasi

Tabel 5 Hasil Uji Autokorelasi

\begin{tabular}{|c|c|c|c|c|c|}
\hline \multicolumn{6}{|c|}{ Model Summary $^{\mathbf{b}}$} \\
\hline Model & $\mathrm{R}$ & $\begin{array}{c}\mathrm{R} \\
\text { Square }\end{array}$ & $\begin{array}{c}\text { Adjusted R } \\
\text { Square }\end{array}$ & $\begin{array}{l}\text { Std. Error } \\
\text { of the } \\
\text { Estimate }\end{array}$ & $\begin{array}{l}\text { Durbin- } \\
\text { Watson }\end{array}$ \\
\hline 1 & $0,430^{\mathrm{a}}$ & 0,185 & 0,125 & 0,484 & 2,285 \\
\hline
\end{tabular}

Sumber: Hasil Pengolahan Data (2019)

Tabel 5 menunjukkan bahwa nilai Durbin Watson adalah sebesar 2,285. Nilai ini akan dibandingkan dengan nilai tabel alpha 5\%, jumlah sampel (n) sebesar 30 dan 
jumlah variabel independen sebesar $2(\mathrm{k}=2)$, maka didapatkan nilai tabel Durbin Watson yaitu $\mathbf{d l}=\mathbf{1}=\mathbf{2 8 3 7}$ dan $\mathbf{d u}=1$ 1,5666. Dapat disimpulkan dalam penelitian ini menggunakan kriteria nomor 5 yaitu : $\mathrm{H}_{0}=\mathrm{du}<\mathrm{d}<(4-\mathrm{du}), \mathbf{H}_{\mathbf{0}}=\mathbf{1 , 5 6 6 6}<\mathbf{2 , 2 8 5}<$ $\mathbf{2 , 4 3 3 3}$ (4-1,5666). Hipotesis diterima karena tidak ada terjadi autokorelasi positif atau negatif.

\section{Uji Analisis Regresi Linear Berganda}

Analisis regresi berganda digunakan untuk mengetahui pengaruh variabel independen terhadap variabel dependen. Variabel independen terdiri dari Kemudahan Penerapan Sistem e-filing dan Pengetahuan Perpajakan, sedangkan variabel dependennya adalah kepatuhan wajib pajak.

Tabel 6 Hasil Uji Regresi Linear Berganda

\begin{tabular}{lccccc}
\hline \multicolumn{6}{c}{ Coefficients $^{\mathbf{a}}$} \\
\hline Model & B & $\begin{array}{c}\text { Unstandardized Standardized } \\
\text { Coefficients } \\
\text { Std. } \\
\text { Error }\end{array}$ & $\begin{array}{c}\text { Coefficients } \\
\text { Eeta }\end{array}$ & t & Sig \\
\hline $1 \quad$ (Constant) & 1,905 & 1,016 & & 1,875 & 0,072 \\
$\begin{array}{l}\text { Kemudahan } \\
\text { Penerapan } \\
\text { Sistem e-filing }\end{array}$ & $-0,029$ & 0,261 & $-0,021$ & $-0,111$ & 0,912 \\
$\begin{array}{l}\text { Pengetahuan } \\
\text { Perpajakan }\end{array}$ & 0,496 & 0,216 & 0,439 & 2,296 & 0,030 \\
\hline
\end{tabular}

Sumber: Hasil Pengolahan Data (2019)

Persamaan regresi linear berganda yang diperoleh adalah:

$\mathrm{Y}=1,905-0,029 \mathrm{X}_{1}+\mathbf{0 , 4 9 6} \mathrm{X}_{2}$

Persamaan regresi linear memberikan penjelasan sebagai berikut:

1) Konstanta sebesar 1,905 menjelaskan bahwa apabila semua variabel independen konstan atau sama dengan nol, maka besarnya tingkat kepatuhan wajib pajak orang pribadi sebesar 1,905 satuan.

2) Variabel kemudahan penerapan sistem e-filing $\left(\mathrm{X}_{1}\right)$ memperoleh nilai koefisien sebesar -0,029 yang menunjukkan bahwa apabila penerapan sistem e-filing mengalami peningkatan, maka kepatuhan wajib pajak akan meningkat 1 satuan, maka kepatuhan wajib pajak PT. PLN Tbk (Persero) Tanjung Priok akan menurun 
sebesar 0,029 satuan UP3 dengan asumsi bahwa variabel independen lain dalam kondisi konstan.

3) Variabel pengetahuan perpajakan $\left(X_{2}\right)$ memperoleh nilai koefisien sebesar 0,496 yang menunjukkan bahwa apabila pada variabel pengetahuan perpajakan meningkat 1 satuan, maka kepatuhan wajib pajak PT. PLN Tbk (Persero) UP3 Tanjung Priok akan meningkat sebesar 0,496 satuan dengan asumsi variabel independen lain dalam kondisi konstan.

a. Uji Signifikansi Parameter (Uji t)

Uji stastistik $\mathrm{t}$ menunjukkan seberapa jauh pengaruh satu variabel independen secara individual dalam menerangkan variabel dependen. Pengujian dilakukan dengan menggunakan tingkat signifikansi $0,05(\alpha=5 \%)$ (Ghozali, 2016).

Tabel 7 Hasil Uji Signifikansi Parameter (uji t)

\begin{tabular}{|c|c|c|c|c|c|c|}
\hline \multicolumn{7}{|c|}{ Coefficients ${ }^{\mathrm{a}}$} \\
\hline \multirow{2}{*}{\multicolumn{2}{|c|}{ Model }} & \multicolumn{2}{|c|}{$\begin{array}{l}\text { Unstandardized } \\
\text { Coefficients }\end{array}$} & \multirow{2}{*}{$\begin{array}{c}\text { Standardized } \\
\text { Coefficients } \\
\text { Beta } \\
\end{array}$} & \multirow[t]{2}{*}{$\mathbf{t}$} & \multirow[t]{2}{*}{ Sig } \\
\hline & & B & Std. Error & & & \\
\hline \multirow{3}{*}{1} & (Constant) & 1,905 & 1,016 & & 1,875 & 0,072 \\
\hline & $\begin{array}{l}\text { Kemudahan Penerapan } \\
\text { Sistem e-filing }\end{array}$ & $-0,029$ & 0,261 & $-0,021$ & $0, \overline{111}$ & 0,912 \\
\hline & Pengetahuan Perpajakan & 0,496 & 0,216 & 0,439 & 2,296 & 0,03 \\
\hline
\end{tabular}

Sumber: Hasil Pengolahan Data (2019)

Hasil yang diperoleh pada tabel 7 adalah sebagai berikut:

1) Nilai signifikansi kemudahan penerapan sistem e-filing sebesar 0,912 lebih besar dari $>5 \%(0,05)$ maka variabel kemudahan penerapan sistem $e$-filing secara parsial tidak berpengaruh terhadap variabel kepatuhan wajib pajak.

2) Nilai signifikansi pengetahuan perpajakan sebesar 0,030 lebih kecil dari 5\% $(0,05)$, maka variabel pengetahuan perpajakan secara parsial berpengaruh positif terhadap variabel kepatuhan wajib pajak.

\section{b. Uji Signifikansi Parameter (Uji F)}

Uji statistik F pada dasarnya menunjukkan apakah semua variabel independen atau bebas yang dimasukkan dalam model mempunyai pengaruh secara bersama-sama 
terhadap variabel dependen atau terikat (Ghozali, 2016). Pengujian dilakukan dengan menggunakan tingkat signifikansi $0,05(\alpha=5 \%)$.

Tabel 8 Hasil Uji Signifikansi Parameter (uji F)

\begin{tabular}{lcccccc}
\hline \multicolumn{7}{c}{ ANOVA $^{\text {a }}$} \\
\hline Model & $\begin{array}{c}\text { Sum of } \\
\text { Squares }\end{array}$ & Df & $\begin{array}{c}\text { Mean } \\
\text { Square }\end{array}$ & F & Sig. \\
\hline 1 & Regression & 1,435 & 2 & 0,718 & 3,067 & $0,063^{\text {b }}$ \\
\cline { 2 - 6 } & Residual & 6,320 & 27 & 0,234 & & \\
Total & 7,755 & 29 & & & \\
\hline
\end{tabular}

Sumber: Hasil Pengolahan Data (2019)

Tabel 8 menunjukkan bahwa nilai signifikan sebesar 0,063>0,05 sesuai dengan dasar pengambilan keputusan dalam uji F. Dapat disimpulkan bahwa kemudahan penerapan sistem e-filing $\left(\mathrm{X}_{1}\right)$, pengetahuan perpajakan $\left(\mathrm{X}_{2}\right)$ secara simultan tidak berpengaruh terhadap kepatuhan wajib pajak (Y).

c. Uji Koefisien Determinasi

d.

Tabel 9 Hasil Uji Koefisien Determinasi

\begin{tabular}{lrrrr}
\hline \multicolumn{5}{c}{ Model Summary $^{\mathbf{b}}$} \\
\hline Model & R & R Square & $\begin{array}{c}\text { Adjusted R } \\
\text { Square }\end{array}$ & $\begin{array}{l}\text { Std. Error of } \\
\text { the Estimate }\end{array}$ \\
\hline 1 & $0,430^{\mathrm{a}}$ & 0,185 & 0,125 & 0,484
\end{tabular}

Sumber: Hasil Pengolahan Data (2019)

Tabel 9 menunjukkan nilai Adjusted $\left(\mathrm{R}^{2}\right)$ sebesar 0,125 atau sama dengan 12,5\%. Hal ini menunjukkan bahwa kepatuhan wajib pajak dipengaruhi oleh variabel kemudahan penerapan sistem e-filing dan pengetahuan perpajakan sebesar $12,5 \%$ sedangkan sisanya $87,5 \%(100 \%$ - 12,3\%) dijelaskan oleh variabel lain di luar model regresi penelitian ini. 


\section{Pembahasan}

a. Pengaruh Kemudahan Penerapan Sistem $e$-filing terhadap Kepatuhan Wajib Pajak Orang Pribadi

Penerapan sistem e-filing memiliki nilai signifikansi sebesar 0,912 atau lebih besar dari > 0,05, yang berarti penerapan sistem e-filing secara parsial tidak berpengaruh terhadap variabel kepatuhan wajib pajak, sehingga hipotesis pertama ditolak.

Penelitian ini tidak sejalan dengan penelitian yang dilakukan oleh Sulistyorini, et al (2017) dan Agustiningsih \& Isroah (2016) yang mengemukakan bahwa penerapan sistem e-filing tidak berpengaruh terhadap kepatuhan wajib pajak dalam penyampaian SPT Tahunan. Hal ini disebabkan karena masih terdapat wajib pajak orang pribadi yang belum sadar akan kewajiban perpajakannya. Jika wajib pajak orang pribadi sadar dan menunaikan kewajiban perpajakannya, sudah pasti jumlah wajib pajak orang pribadi yang melaporkan SPT Tahunannya juga akan meningkat seiring dengan meningkatnya jumlah wajib pajak orang pribadi yang terdaftar.

\section{b. Pengaruh Pengetahuan perpajakan berpengaruh positif terhadap kepatuhan wajib pajak}

Pengetahuan perpajakan memiliki nilai signifikansi sebesar 0,03 lebih kecil dari < 0,05, yang berarti bahwa pengetahuan perpajakan secara parsial berpengaruh positif terhadap variabel kepatuhan wajib pajak, sehingga hipotesis kedua diterima.

Penelitian ini sejalan dengan penelitian yang dilakukan oleh Rahayu (2017) dan Ilhamsyah et al (2016) yang mengemukakan bahwa pengetahuan perpajakan dan kesadaran wajib pajak berpengaruh positif terhadap kepatuhan wajib pajak.

Semakin tinggi pengetahuan perpajakan maka semakin tinggi pula kepatuhan wajib pajak orang pribadi. Hal ini dapat disebabkan karena tingginya pengetahuan perpajakan melalui moderasi seperti internet, sosialisasi dan sebagainya. Sebaliknya semakin rendah pengetahuan perpajakan maka semakin rendah kepatuhan wajib pajak orang pribadi karena kurangnya kesadaran wajib pajak akan kewajiban dan sanksi perpajakan. 


\section{Kesimpulan}

Hasil penelitian menunjukkan bahwa kemudahan penerapan sistem $e$-filing tidak berpengaruh terhadap kepatuhan Wajib Pajak Orang Pribadi dalam penyampaian SPT Tahunan pada PT. PLN (Persero) Tbk UP3 Tanjung Priok. Hal ini dapat disebabkan karena masih ada wajib pajak orang pribadi yang belum sadar akan kewajiban perpajakannya. Jika wajib pajak orang pribadi sadar dan menunaikan kewajiban perpajakannya, sudah pasti jumlah wajib pajak orang pribadi yang melaporkan SPT Tahunannya juga akan meningkat seiring dengan meningkatnya jumlah wajib pajak orang pribadi yang terdaftar. Hasil penelitian menunjukkan bahwa pengetahuan perpajakan berpengaruh positif terhadap kepatuhan wajib pajak. Hal ini karena semakin tinggi pengetahuan perpajakan maka semakin tinggi pula kepatuhan wajib pajak orang pribadi. Hal ini dapat disebabkan karena tingginya pengetahuan perpajakan melalui moderasi seperti internet, sosialisasi dan lain-lain.

\section{Referensi}

Agustiningsih, W, dan Isroah, I., 2016. Pengaruh Penerapan E-Filing, Tingkat Pemahaman Perpajakan Dan Kesadaran Wajib Pajak Terhadap Kepatuhan Wajib Pajak Di KPP Pratama Yogyakarta. Nominal, Barometer Riset Akuntansi dan Manajemen, 5(2).

Ghozali, I., 2016. Aplikasi Analisis Multivariete dengan Program IBM SPSS 23, Edisi Delapan. Penerbit Universitas Diponogoro. Semarang.

Handayani, S.W., Faturokhman, A. dan Pratiwi, U., 2012. Faktor-faktor yang mempengaruhi kemauan membayar pajak wajib pajak orang pribadi yang melakukan pekerjaan bebas. Simposium Nasional Akuntansi XIV.

Hanifah, H. dan Wijaya, I., 2019. Tax Planning Atas Pajak Penghasilan Badan Pada PT SCI. Jurnal Online Insan Akuntan, 4(1), pp.1-10.

Ilhamsyah, R., 2016. Pengaruh Pemahaman dan Pengetahuan Wajib Pajak Tentang Peraturan Perpajakan, Kesadaran Wajib Pajak, Kualitas Pelayanan, dan Sanksi Perpajakan Terhadap Kepatuhan Wajib Pajak Kendaraan Bermotor (Studi SAMSAT Kota Malang). Jurnal Mahasiswa Perpajakan, 8(1).

Peraturan Direktur Jenderal Pajak Nomor PER-39/PJ/2011 yang sudah diperbaharui dengan Peraturan Direktur Jenderal Pajak terbaru, Nomor PER-1/PJ/2014 tentang tata cara penyampaian Surat Pemberitahuan bagi Wajib Pajak Orang Pribadi yang menggunakan formulir 1770 S atau 1770SS secara e-filing melalui website Direktorat Jenderal Pajak (www.pajak.go.id).

Rahayu, N., 2017. Pengaruh pengetahuan perpajakan, ketegasan sanksi pajak, dan Tax amnesty terhadap kepatuhan wajib pajak. Akuntansi Dewantara, 1(1), pp.15-30.

Resmi, S., 2017. Perpajakan Teori dan Kasus Edisi 10.

Sulistyorini, M., Nurlaela, S. and Chomsatu, Y., 2017. Pengaruh Penggunaan Sistem Administrasi E-Registration, E-Billing, E-Spt, Dan E-Filling Terhadap Kepatuhan 
Wajib Pajak (Studi Pada Wajib Pajak Orang Pribadi Di RSUD Dr. Moewardi Surakarta). In Prosiding Seminar Nasional \& Internasional (Vol. 1, No. 1).

Yogatama, A. and Meiranto, W., 2014. Analisis Faktor-Faktor yang Mempengaruhi Kepatuhan Wajib Pajak Orang Pribadi (Studi di Wilayah KPP Pratama Semarang Candisari) (Doctoral dissertation, Fakultas Ekonomika dan Bisnis). 